\title{
Academic Procrastination among Gifted and Ordinary Students and its Relationship with Some Variables
}

\author{
Ziad Khamis El-tah ${ }^{1, *} \&$ Wael Mohammad Alsharman ${ }^{2}$ \\ ${ }^{1}$ Educational Psychology, Dept. of Psychological Sciences and Special Education, Al al-Bayt \\ University, Jordan \\ ${ }^{2}$ Special Education, Dept. of Psychological Sciences and Special Education, Al al-Bayt \\ University, Jordan \\ *Correspondence: Educational Psychology, Dept. of Psychological Sciences and Special \\ Education, Al al-Bayt University. E-mail: dr.altah@aabu.edu.jo
}

Received: July 10, 2017 Accepted: August 2, 2017 Published: September 1, 2017

doi:10.5296/ije.v9i3.11224 URL: https://doi.org/10.5296/ije.v9i3.11224

\begin{abstract}
This study aims at identifying the academic procrastination among a sample of gifted and ordinary students and its relationship with some variables. It consists of 151 students: (74 are gifted students from King Abdullah II School of Excellence, whereas 77 are ordinary students). The researchers designed a questionnaire of academic procrastination for this study. Then its validity and reliability were verified. To answer the study questions, means, standard deviations, percentages, one way analysis of variance $(2 * 2)$ and T-test were used. The results show that the academic procrastination of gifted students is low (mean score 44.36, standard deviation 10.051). The percentage of gifted students with academic procrastination is 37.8. However, the academic procrastination of ordinary students is high with a mean of 50.94 and a standard deviation 10.20, and the mean of ordinary students with academic procrastination is 58.4. Moreover, the results show that there are no statistical significant differences at $\alpha \leq 0.05$ in academic procrastination among gifted students due to gender, grade and the interaction between them. However, there are significant differences at $\alpha \leq 0.05$ in academic procrastination among ordinary students due to gender. In addition, there are no statistical significant differences at $\alpha \leq 0.05$ in academic procrastination due to grade and interaction between gender and grade. Thus, there are statistical significant differences at $\alpha \leq$ 0.05 between gifted and ordinary in academic procrastination in favor of the ordinary students. This study recommends that counseling programs should be considered to reduce the negative effects of academic procrastination among gifted and ordinary students.
\end{abstract}

Keywords: academic procrastination, gifted students, ordinary students, gender, grade 


\section{Introduction}

Giftedness is one of the hot topics that caught the attention of researchers in educational fields. Therefore, researchers try to study the characteristics that distinguish gifted students from others. Because identifying these characteristics helps them to raise the ordinary students to reach the traits of giftedness and stimulate their abilities. Jordan is one of the first Arab countries which pay attention to its gifted students. The law in Jordan gives authority to the Ministry of Education to establish educational institutions for gifted students. Therefore, the ministry can determine its programs, including the incentives of its employees (issued under section (b) article (41) and (45) of the Education Law No. (3) of 1994). (Ministry of Education, ${ }^{(1)} 2017$ )

Interest in gifted students in Jordan has grown rapidly. In 1997/1996, the government implemented the first program to take care of the gifted students. This program named Pioneer Center was equipped with educational facilities, qualified administrative and educational staff. In 2003/2002, another program has been developed for gifted students called The Resources Rooms for Gifted Students. This newly invented program was developed in areas where the services of the pioneer centers are not available, According to the ministry of education statistics in the academic year 2012/2011, the number of resources rooms were (52) that serve (1805) students. In 2012/2013, other (18) resources rooms for gifted students were developed in various areas in Jordan. In 2011, an independent department for giftedness programs was established under the authority of the Administration of Special Education in the Ministry of Education (Ministry of Education, ${ }^{(2)}$ (2017)

Attention to gifted students has increased because they have positive characteristics that make them motivated and organized. These characteristics distinguish them from others in achievement, behavior and other abilities, including recognition of symbolic systems, abstract ideas, curiosity, independence, focusing attention, good memory, loving reading, many interests, early linguistic development, early moral maturity, leadership, good humor, activity and vitality, high ability in a particular field, rapid learning, enjoying learning, empathy, creativity and imagination, and general intelligence ability (Ayasreh \& Ismail, 2012; Garwan, 2012; Subotnik, Olszewski-Kubilius \& Worrell, 2011).

Gifted students may have negative traits like feeling bored, annoying others, loving appearance, school routines rejection, rebellion. (Aljughaiman, 2008). One of the most controversial gifted students characteristics among researchers is the perfectionism. It means that the gifted students seek to be flawless and overstated by setting high standards of performance, and this is accompanied by an excessive tendency to evaluate behavior critically (Flett \& Hewitt, 2002). Some researchers consider perfectionism negative characteristic and others consider it as positive based on how it is directed. It is positive when it involves high awareness of performance because it becomes an incentive for self-actualization and ideals (Silverman, 2007). In addition, perfectionism can be negative if it leads to inertia and failure to accomplish the tasks assigned for them and delay it on time, which makes them procrastinating students until they accomplish what is required to the fullest and perfection (Jadidi, Mohammadkhani, Tajrish, 2011; Steel, 2007). found that 
students who have high degree of perfectionism are more likely to delay academic tasks than students who have a low degree of perfectionism.

Procrastination can generally be defined as a voluntary postponement of tasks to be performed at the last minute despite the disadvantages of this delay (Klingsieck, 2013). Therefore, academic procrastination can be defined as the postponement of academic tasks for some reasons (Akbay and Gizir, 2010). Gifted students study with ordinary students in the same school environment and live in the same society characterized by technological development at all levels and aspects, providing so many of the reinforces such as electronic and entertainment games, smart phones, tablets, and Internet and other modern application programs. All of these facilities lead to wasting their time and may force them to procrastinate academic tasks. As a result, their academic achievement is negatively affected, and so their mental abilities decline.

Academic procrastination is considered a negative phenomenon practiced by gifted and ordinary students. It has many effects on human behavior. It negatively affects life management, production and how the brain deals with the requirements of life (Ozer, 2011). Procrastination has positive effects if the delay leads to learning more and gathering information that helps to understand the available data (Chu and Choi, 2005).

Academic procrastination affects the individual's life. There is an inverse relationship between self-esteem and procrastination. If individual's self-esteem was weak, procrastination is great (Klassen, Krawchuk, and Raijani, 2007). However, there is a negative relationship between the behavior of the individual who seeks perfectionism in his/her actions and procrastination. It is found that there is a negative relationship between self-oriented perfectionism and academic procrastination, whereas a positive relationship is found between self-oriented perfectionism and life satisfaction. There is no relationship between other-oriented perfectionism, academic procrastination and life satisfaction, and there is a direct correlation between fear of failure and academic procrastination (Capan, 2010; Seo, 2008).

There is an inverse relationship between motivation and procrastination (Balkis, 2006; Cohen, and Ferrari, 2008; Diaz-Morales, Klassen, Krawchuk, \& Raijani, 2007; Lee, 2005). There is also an inverse relationship between the individual's confidence and the ability to achieve and tendency to procrastinate (Odaci, 2011; Steel, 2007; Wolters, 2003). Procrastination also affects the overall individual's performance. This means that the procrastinate persons tend to perform less than non- procrastinating persons (Steel, Brothen, \& Wambach, 2001). The procrastinate individuals are more infelicity; this takes place as a result of their procrastinate actions and wasting time (Tice \& Baumeister, 1997).

Some studies have indicated that there are no statistical significant differences between males and females in procrastination (Alexander and Onwuegbuzie, 2007; Kachgal, Hansen, and Nutter, 2001; Watson, 2001). Other studies show that there are statistical significant differences in procrastination in favor of females (Doyle \& and Paludi, 1998). However, other studies show that these differences are in favor of males (Akinsola, Tella, \& Tella, 2007; Balkis, 2006; Balkis \& Duru, 2009; Else- Quest, Hyde, Goldsmith, \& Van Hulle, 2006). 


\section{Previous Studies}

Abu Ghazal, (2012) identified the prevalence of academic procrastination and its reasons from the point of view of university students. The sample study consists of 751 students: (222 males and 529 females) from Yarmouk University. The results show that $25.2 \%$ of the students were with high procrastination, $57.7 \%$ of them had moderate procrastination and $17.2 \%$ with low procrastination. And there were statistically significant differences in the prevalence of academic procrastination due to the academic level variable. The rate of procrastination was higher for students in the fourth year than those other levels. The results also revealed that the strongest reason for academic procrastination was fear of failure. The results showed there were no statistically significant differences due to gender and academic specialization.

Bezci, \& Vural (2013) identified the impact of academic procrastination and gender on achievement in science. A sample consisted of (4725) students from basic public schools: (2335 female and 2371 male). The results show an inverse relationship between academic procrastination and achievement. In addition, the female students show higher achievement in science than male students.

Al-silami (2015) identified the level of practicing academic procrastination and the level of motivation and the relationship between them in the light of the following variables: academic level and geographical location in a sample of Umm Al-Qura University students. It consisted of 160 students from Makkah and AL laith Colleges. The results show that the levels of academic procrastination and self-motivation were normal, and there were differences in the level of academic procrastination due to the geographical location in favor of the students in AL Laith College. There was also a negative significant correlation between academic procrastination and motivation.

Seo (2013) examined the relationship between procrastination (active and passive) and academic motivation. The study sample consisted of 278 university students. The results show that the high identification and low external regulation increased active procrastination, and high external regulation and low intrinsic motivation increased passive procrastination. The findings also revealed that active procrastination was inversely correlated to passive procrastination.

Abu-Zrieq and Jaradat (2013) examined the effect of negative self-statements modification in reducing academic procrastination and improving academic self-efficacy among a sample of 33, randomly assigned into control and experimental groups. The results indicated that modifying negative self-statements decreased academic procrastination and improve selfefficacy of both post and trace measurements in the experimental group compared with the control group.

Ozer and Ferrari (2011) attempted to find gender- role differences in academic procrastination. The study sample consisted of (214) Turkish students in secondary schools. The results of the study showed that the Turkish students have four reasons for procrastination, namely; perfectionism, averseness of task, rebellion against control, and risk 
taking. In addition, the results reveal there was a significant main effect for gender roles on academic procrastination excuses. Specifically, adolescents with undifferentiated gender -roles explained their reasons for academic procrastination more than adolescents with masculine gender-role because of the task averseness. Furthermore, Turkish adolescents with undifferentiated gender-role orientation claimed the excuse of risk-taking for their academic procrastination, more than adolescents with femininity and androgynous gender-role.

El-Rabeea, shawashreh \& Hijazi (2014) examined the relationship between academic procrastination and thinking style among Yarmouk University students and Jordanian university of Science Technology students. The sample consisted of $580 \mathrm{BA}$ and MA students (188 males and 392 females). The results revealed that the prevalent thinking style are structural, ideal, scientific, analytical and realistic, respectively. It also showed that there is a positive correlation between academic procrastination and thinking style. There were significant differences in academic procrastination and the five thinking styles due to the university variable in favor of Jordanian University of Science and Technology. There were no significant differences in academic procrastination due to gender and study level variables.

Williams, Shannon, Stark, and Foster (2008) tested the relationship among self-compassionate attitudes, motivation, and procrastination tendency. The study consists of (63) undergraduate students. The results of the study showed that students with high self-compassion reported dramatically less motivation anxiety and procrastination tendency than those with low or moderate self-compassion.

El-tah (2015) investigated the relationship between academic procrastination and Meta Cognitive-strategies. The study sample consisted of 326 students from Al al-Bayt University. The results indicated that $33.6 \%$ of the sample had low academic procrastination while 66.4 had high academic procrastination. He reported significant differences in academic procrastination due to the variables of gender, college and the interaction between gender*college and age*college. The results also revealed no significant differences in academic procrastination due to the age variable, and indicated that there was a negative relationship between academic procrastination and all Meta Cognitive-strategies (self-direction, self-monitoring, self-evaluation, self-correction, and self-control).

\section{Study Questions}

Experts in various fields of education, especially psychology and special education focus their attention on gifted students. This is because gifted students have academic abilities which make them distinctive from the other students. This has raised the importance of studying the characteristics of these students. Educators can have better understanding of the relationship between these characteristics and the abilities that distinguish these students from others. It is worth mentioning that academic procrastination is one of the characteristics that can affect negatively academic achievement. This study was an attempt to understand the prevalence of academic procrastination among gifted students compared with ordinary students, and its relation with some variables like gender and grade. Therefore, this study 


\section{Macrothink}

International Journal of Education

ISSN 1948-5476

2017, Vol. 9, No. 3

attempts to answer: what is the prevalence of academic procrastination among gifted students at Mafraq in Jordan? through answering the following questions:

1. What is the prevalence of academic procrastination among gifted students?

2. What is the prevalence of academic procrastination among ordinary students?

3. Are there any significant differences in academic procrastination among gifted students due to the variables of gender and grade, and the interaction between them?

4. Are there significant differences in academic procrastination among ordinary students due to the variables of gender and grade, and the interaction between them?

5. Are there any significant differences in academic procrastination between gifted students and ordinary students?

\section{Limitations}

The results of this study have the following limitations:

- The sample was restricted to gifted and ordinary students enrolled in 9th and 10th grades at King Abdullah II School for Excellence and public schools at Mafraq in Jordan in the second semester in the academic year 2015/2016.

- It also limited by the psychometric characteristics of the instruments used in it.

\section{Methodology}

In this study, the researchers used the descriptive method to meet the designated objectives and answer its questions. Statistical characteristics such as mean and standard deviation were computed. In addition, the percentages were calculated to answer first and second questions. To answer the third and fourth questions, two way analysis of variance $(2 * 2)$ was applied. Finally, the t-test was used for independent samples to answer the fifth question.

\section{Procedures}

\subsection{Sample}

The sample of this study consisted of 151 randomly selected students. Seventy four of them were gifted students in the King Abdullah II School of Excellence: (44 were $9^{\text {th }}$ graders and $3010^{\text {th }}$ graders. Amongst the sample, 33 were males and 41 were females). In addition, 77 ordinary students were randomly selected: (forty one of them were males while 36 were females, thirty eight of them were the $9^{\text {th }}$ graders, but 39 were from $10^{\text {th }}$ grade). Table (1) shows the distribution of the sample according to the variables under consideration. 


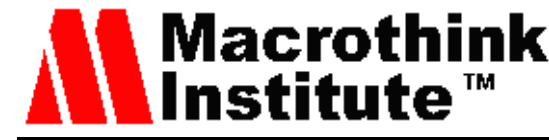

Table 1. Distribution of the Sample of the Study and the Study Variables

\begin{tabular}{lcccc}
\hline Students & Variable & & $\mathrm{N}$ & Total \\
\hline \multirow{3}{*}{ Gifted } & Gender & Male & 33 & \\
& & Female & 41 & 74 \\
& Grade & $9^{\text {th }}$ & 44 & \\
& & $10^{\text {th }}$ & 30 & \\
\multirow{4}{*}{ Odinary } & Gender & Male & 41 & \\
& & Female & 36 & 77 \\
& Grade & $9^{\text {th }}$ & 38 & \\
& & $10^{\text {th }}$ & 39 & \\
\multicolumn{2}{c}{ Total } & & &
\end{tabular}

\subsection{Instrument}

Academic procrastination scale:

After reviewing some of the previous theoretical literature and a number of academic procrastination scales used in the studies such as Lay (1986), Solomon and Rothblum (1994), Abu Ghazal (2012), 45 statements were written to measure academic procrastination. These statements were securitized by 8 experts in special education, educational psychology and psychological measurement to obtain face validity through judging the adequacy of the statements to measure academic procrastination and the linguistic formulation of these statements. Upon the notes given by the jury, some statements were modified and others deleted. The initial edition consisted of (31) statements. Therefore, the scale was applied to a trial sample which was not included in the study sample. It consisted of 24 students. The data collected from this sample included correlation coefficient between the score of each statement and the total score of the scale, where 7 statements were deleted because their correlations with the total score of the scale were not significant. Therefore, the scale consisted of 24 statements and had constructive validity, and 9 statements were negative: (1, $3,8,15,16,17,19,21$, and 24). From the data collected from the trial sample, reliability of the scale was obtained in two ways: (i) the internal consistency by getting Cronbach alpha 0.85 , and (ii) test-retest with a period of ten days between the test and the re-test. The correlation coefficient between the two applications was 0.80 , which is statistically significant at $\alpha \leq 0.001$. All these statistics were suitable to meet this study objectives. Thus, the total score on the scale ranged from 24-72. Accordingly, the student who had a score less than (48) was considered with low procrastination, while the student who had a score of 48 or more was considered to be highly procrastinated.

\section{Results and Discussion}

To answer the first question: what is the prevalence of academic procrastination among gifted students? The mean and the standard deviation of the sample of gifted students' scores on the 
scale of academic procrastination are obtained (mean $=44.36$, standard deviation $=10.05$ ). This means that the academic procrastination among the gifted students was low. This can be explained by the fact that gifted students have cognitive and emotional characteristics that make them more aware of the importance of doing their academic and social duties as well as tasks on time. Pertaining the prevalence of academic procrastination among them, the percentage of students who had a score less than 48 as students who are not academically procrastinators was $62.2 \%$, However, the percentage of gifted students who had a score 48 or above as students with academic procrastination and was $37.8 \%$.

It can be noted that the percentage of not academically procrastinators students is almost twice the percentage of gifted students with academic procrastination. Hence, academic procrastination is not a general phenomenon for gifted students. A simple percentage of academic procrastination can be attributed to certain factors such as socialization poverty and family problems experienced by some gifted students. In addition, some psychological characteristics like lack of motivation and emotional and cultural deprivation, and some emotional characteristics such as perfectionism. All of these factors can increase the academic procrastination, as noted by Jadidi, Mohammadkhani \& Tajrishi (2011). In addition, academic procrastination could happen because of high expectations from parents, peers and society.

To answer the second question: What is the prevalence of academic procrastination among ordinary students? The mean and the standard deviation of the sample of ordinary students' scores on the scale of academic procrastination were obtained. The mean was 50.94 with a standard deviation of 10.20 . This means that the academic procrastination among ordinary students was high. As to the prevalence of academic procrastination among them, the percentage of students who had a score less than 48 as students who were not academically procrastinators was $41.6 \%$, as well as the percentage of ordinary students who had a score of 48 or more as students with academic procrastination was $58.4 \%$.

This result can be interpreted by considering several points. The first is the weakness of the educational system which may motivate ordinary students to delay the completion of the required tasks. In addition, the weak and sagging family authority also increases the prevalence of academic procrastination among ordinary students. Moreover, peers are considered one of the most important things that increase the prevalence of academic procrastination among ordinary students. This is because many ordinary students spend most of their time with their peers, and create a lot of arguments and reasons to waste their time. Furthermore, lack of motivation, frustration, fear of the future, and the high rate of unemployment among young people may help to double procrastinate among ordinary students. This result agreed with many previous studies that focused on academic procrastination and found that there is an increase in academic procrastination among ordinary students (El-tah, 2015; Bezci \& Vural, 2013; Abu Ezreiq \& Jaradat, 2013)

The third question of the study reads: Are there significant differences in academic procrastination among gifted students due to the variables (gender and grade) and its interaction? To answer this question, the mean and standard deviation were calculated based 
on the variables under examination; see Table 2.

Table 2. Means and Standard deviations of Academic Procrastination Among the Gifted Students According to Variables of Gender and Grade

\begin{tabular}{ccccc}
\hline Variable & & $\mathrm{N}$ & Mean & S.D \\
\hline Gender & Male & 33 & 46.18 & 10.1 \\
& Female & 41 & 42.9 & 9.8 \\
\hline Grade & $9^{\text {th }}$ & 44 & 42.7 & 10.5 \\
& $10^{\text {th }}$ & 30 & 46.8 & 9.0 \\
\hline
\end{tabular}

Table 2 shows that the mean for the gifted males was 46.18 with a standard deviation of 10.1 , while it was 42.9 for the gifted females with a standard deviation of 9.8. Furthermore, the mean of the $9^{\text {th }}$ grade gifted students was 42.7 with a standard deviation of 10.5 . However, the mean of the $10^{\text {th }}$ grade was 46.8 with a standard deviation of 9.0. These figures indicate that there were apparent differences in academic procrastination depending on the gender and grade variables. To examine whether these differences were significant at $\alpha \leq 0.05$, the two way analysis of variance was calculated. Table 3 shows the results of the two way analysis variance.

Table 3. Two Way Analysis of Variance of Differences in Academic Procrastination According to Gender and Grade Variables of the Gifted Students and the Interaction between Them

\begin{tabular}{cccccc}
\hline Source & Sum of Squares & Df & Mean Square & F & Sig. \\
\hline Gender & 172.96 & 1 & 172.96 & 1.756 & 0.189 \\
Grade & 279.48 & 1 & 279.48 & 2.837 & 0.097 \\
Gender*Grade & 0.103 & 1 & 0.103 & 0.001 & 0.974 \\
Error & 6895.355 & 70 & 98.51 & & \\
Corrected Total & 7375.149 & 73 & & & \\
\hline
\end{tabular}

Based on Table 3 the two-way ANOVA indicated no significant main effect of gender, $\mathrm{F}=$ 1.756, $(\alpha=0.189)$, it means that there were no significant differences at $\alpha \leq 0.05$ between the gifted males and females in academic procrastination. And the two-way ANOVA indicated no significant main effect of grade, $F=2.837, \alpha=0.097$, it means that there were also no significant differences in academic procrastination at the $\alpha \leq 0.05$ level among the gifted students in the $9^{\text {th }}$ grade and the $10^{\text {th }}$ grade. This means that there were no statistical significant differences at $\alpha \leq 0.05$ between the gifted students in the $9^{\text {th }}$ and $10^{\text {th }}$ grades. Furthermore, the two-way ANOVA indicated no significant main effect of the interaction between the gender and grade, $F=0.001, \alpha=0.974$, this means that there were no significant 
difference at $\alpha \leq 0.05$ in academic procrastination among the gifted students due to the interaction between gender and grade variables.

It is possible to attribute that to the fact that students at this age have the same personal characteristics whether they are males or females. They have a degree of seriousness, perseverance, sense of responsibility, and task commitment in performing what is required from them with a high degree of completion of tasks on time. Moreover, they belong to the same stage of development whether they are in the $9^{\text {th }}$ or $10^{\text {th }}$ grade which is adolescence, meaning that they are in abstract operational stage, so they have the same cognitive characteristics. This agree with Ozer\& Ferrari (2011) and Abu Ghazal (2012) that gender and grade do not affect academic procrastination. As for the interaction between gender and grade variables, there was no significant difference on academic procrastination, suggesting that each of the variables does not change its impact on academic procrastination if the other variable level changes for the gifted students.

To answer the fourth question of the study: Are there significant differences in academic procrastination among ordinary students due to the variables (gender and grade)? The means and standard deviations were calculated according to the study variables; Table 4 shows this.

Table 4. Means and Standard Deviations of Academic Procrastination of Ordinary Students According to the Variables of Gender and Grade

\begin{tabular}{ccccc}
\hline Variable & & $\mathrm{N}$ & Mean & SD \\
\hline Gender & Male & 41 & 46.71 & 7.4 \\
& Female & 36 & 55.75 & 10.88 \\
Grade & $9^{\text {th }}$ & 38 & 49.89 & 10.36 \\
& $10^{\text {th }}$ & 39 & 51.95 & 10.7 \\
\hline
\end{tabular}

According to the previous table, it can be noted that the mean of ordinary males was 46.71 with a standard deviation of 7.4 while the mean of ordinary female was 55.75 with a standard deviation of 10.88 , and the mean of $9^{\text {th }}$ grade was 49.89 with a standard deviation 10.36 . On the other hand, the mean of the $10^{\text {th }}$ grade was 51.95 with a standard deviation of 10.7 . This indicates that there were apparent differences in academic procrastination for the gender and grade variables. In order to examine whether these differences were significant at the $\alpha=0.05$, the two way analysis of variance was used. Table 5 shows the results.

From Table 5 the two-way ANOVA indicated significant main effect of gender, $\mathrm{F}=17.953, \alpha$ $=0.000$ ), it means that there were significant difference at $\alpha=0.05$ between ordinary males and females in academic procrastination. Going back to Table 4, it can be noted that the males received a mean of 46.71 while the females obtained a mean of 55.75. This means that the ordinary female were more procrastinating than the ordinary males. Furthermore, it can be noted from Table 5 the two-way ANOVA indicated no significant main effect of grade, $\mathrm{F}$ $=0.433, \alpha=0.643$, that means there were no significance differences at $\alpha=0.05$ between the ordinary students in the $9^{\text {th }}$ and $10^{\text {th }}$ grades. Also the two-way ANOVA indicated no significant main effect of the interaction between the gender and the grade, $\mathrm{F}=0.029, \alpha=$ 
0.864 , this means that there was also no significant difference at the $\alpha=0.05$ in academic procrastination between ordinary students due to the interaction between the gender and grade variables.

Table 5. Two Way Analysis of Variance of Differences in Academic Procrastination According to Gender and Grade Variables of Ordinary Students and the Interaction between Them

\begin{tabular}{cccccc}
\hline Source & Sum of squares & df & Mean Square & F & Sig. \\
\hline Gender & 1543.32 & 1 & 1543.32 & 17.953 & 0.000 \\
Grade & 53.527 & 1 & 53.527 & 0.643 & 0.433 \\
Gender*Grade & 2.522 & 1 & 2.522 & 0.029 & 0.864 \\
Error & 6275.398 & 73 & 85.964 & & \\
Corrected Total & 7900.675 & 76 & & & \\
\hline
\end{tabular}

This result showed significant differences between males and females in academic procrastination in favor of females. This can be interpreted by the different socialization degree practiced by males and females in the Jordanian society. That is, socialization for males focus on achievement and authority and these are social requirements; it is their duty to bring money and to take care of females, while female socialization focus on children caring and housework. Therefore, females can procrastinate their academic tasks to help their mothers in the housework which is their first interest. Several previous studies have shown that the academic procrastination of ordinary students at this stage was high (El-tah, 2015; Ozer \& Ferrari, 2011).

The results show that there was no significant difference in procrastination due to the variable of grade. This result can be explained by the fact that students in the sample from the 9th and 10th grades belong to the same stage which has the same cognitive characteristics and interests. The results also showed that there was no significance differences in academic procrastination due to the interaction between the gender and grade variables. This means that neither variable changes its effect on academic procrastination by changing the levels of the other variable among ordinary students.

The fifth question was Are there significant differences in academic procrastination between gifted students and ordinary students? To answer the question, means and standard deviations for the scores of the gifted and ordinary students on the scale of academic procrastination were computed; Table 6 illustrates the results. 
Table 6. Means and Standard Deviations for the Scores of Gifted and Ordinary Students on the Scale of Academic Procrastination

\begin{tabular}{cccc}
\hline Students & N & Mean & S.D \\
\hline Gifted & 74 & 44.36 & 10.051 \\
Ordinary & 77 & 50.94 & 10.2 \\
\hline
\end{tabular}

According to the previous table, the mean for the gifted students was 44.36 with a standard deviation of 10.051 , while it was50.94 for the ordinary students with a standard deviation of 10.2 , indicating that there were apparent differences between the gifted and ordinary students in academic procrastination. To find out if these differences were significant, the $\mathrm{T}$ test for the independent samples was used, and table (7) show the results.

Table 7. T-Test for Independent Samples of the Difference between Gifted and Ordinary Students on Academic Procrastination

\begin{tabular}{cccc}
\hline $\mathrm{T}$ & Mean Difference & df & Sig. (2-tailed) \\
\hline 3.97 & 6.7 & 149 & 0.000 \\
\hline
\end{tabular}

Table (7) shows that the difference between the gifted students and ordinary students on academic procrastination was significant, with ( $t$ ) value of $3.97, \alpha=0.000$. The table also shows that the mean for the gifted students was (44.36) with a standard deviation of (10.051), while for the ordinary students it was (50.94) with standard deviation of 10.2. This means that the ordinary students were practicing academic procrastination more than the gifted students. This result can be attributed to the characteristics that distinguish the gifted students from the ordinary students in terms of their achievement motivation, their perseverance and their love to be good enough in their work, so they do not procrastinate their academic tasks, but they work until accomplish them.

\section{Conclusions}

The main conclusion of this study is that both the gifted and ordinary students procrastinate their academic tasks, but the ordinary students procrastinate their academic work more than the gifted students. This is because the gifted students differ from ordinary students in terms of personal and cognitive characteristics. This results may help school counselors to develop counseling programs for both gifted and ordinary students according to their characteristics to reduce academic procrastination. Also, they may give the searchers clues to study the negative characteristics that characterize the gifted students and can increase their academic procrastination to learn how to reduce them.

This study raises the issue that the personal and cognitive characteristics of the gifted students make them similar in academic procrastination regardless of their gender and grade. As to the 
ordinary students, the cognitive characteristics make them similar in academic procrastination in different grades, but different socialization makes academic procrastination more common among females. This gives the educational decisions makers feedback that may help them to take correct decisions about programs for both gifted and ordinary students, and can motivate researchers to study academic procrastination among gifted and ordinary students in other settings to identify other factors that may have relationships with academic procrastination.

\section{References}

Abu Ghazal, M. (2012). Academic Procrastination: Its spread and causes from the point of view of university students. Jordan Journal of Science in Education, 8(2), 131-149.

Abu-Zreik, M., \& Jaradat, A. (2013). Effects of the Modification of Negative Self Statements on Reducing Academic Procrastination and Improving Academic Self-Efficacy. Jordanian Journal of Educational Sciences, 9(1), 199-236.

Akbay, S., \& Gizir, C. (2010). The College Student' Academic Procrastination Behavior According To Gender. Mersin University Journal of the Faculty of Education, 6(1), 60-78.

Akinsola M., Tella A., \& Tella A. (2007). Correlates of academic procrastination and mathematics achievement of university undergraduate students. Eurasia J. Maths. Scien. Technol. Educ., 3(4), 363-370.

Alexander S., \& Onwuegbuzie J. (2007). Academic procrastination and the role of hope as a coping strategy. Pers. Indiv Differ., 42(1), 1301-1310. https://doi.org/10.1016/j.paid.2006.10.008

Aljughaiman, A. (2008). Gifted Education in the Arab World in Teacher Education Programs, Saudi Arabia: Scientific book of the Arab Organization for Culture, Science and Education.

Al-silami, T. (2015). Levels of academic procrastination and self-motivation and the relationship between them among students of Makkah and Laith colleges in Saudi Arabia. Journal of Educational and Psychological Sciences, 16(2), 639- 664.

Ayasreh, S., \& Ismail, N. (2012). Traits and characteristics of gifted and outstanding students as a basis for the development of their detection standards. The Arab Journal for the Development of Excellence, 4(3), 97-115.

Balkis, M. (2006). The relationships between student teachers' procrastination behaviors and thinking styles and decision making styles. Unpublished $\mathrm{PhD}$ Thesis. Dokuz Eylül University Institute of Education Sciences: zmir.

Balkis, M., \& Duru E. (2009). Prevalence of academic procrastination behavior among preservice teachers, and its relationship with demographics and individual preferences. $J$. Theory Practice Educ., 5(1), 18-32. 
Bezci, F., \& Vural, S. (2013). Academic procrastination and gender as predictors of science achievement. Journal of educational and instructional studies in the world, 3(2), 64-68.

Capan, B. (2010). Relationship among perfectionism, academic procrastination and life satisfaction of university students. Procedia. Soc. Behavioral. Sci., 5(1), 1665-1671. https://doi.org/10.1016/j.sbspro.2010.07.342.

Chu, A., \& Choi, J. (2005). Rethinking procrastination: Positive effects of "active" procrastination behavior on attitudes and performance. Journal of Social Psychology; Philadelphia, 14(1), 245-264. http://dx.doi.org/10.3200/SOCP.145.3.245-264

Díaz-Morales, J., Cohen J., \& Ferrari J. (2008). An integrated view personality styles related to avoidant procrastination. Pers. Indiv. Differ., 45(6), 554-558. https://doi.org/10.1016/j.paid.2008.06.018

Doyle J., \& Paludi M. (1998). Sex and gender: The human experience (4 ${ }^{\text {th }}$ Ed.). San Francisco: McGraw-Hill.

El- Rabeea, F., Shawashreh, O., \& Hijazi, T. (2014). Academic Procrastination \& Thinking Styles among University Students in Jordan. Al-Manarah, 20(AB), 199-236.

Else-Quest, N. Hyde, J. Goldsmith, H. \& Van, C. (2006). Gender differences in temperament: A meta- analysis. Psychological Bulletin, 132(1), 33-72. https://doi.org/10.1037/0033-2909.132.1.33

El-tah, Z. (2015). Academic procrastination and its relationship with meta cognitive strategies among a sample of university students. Journal of Education, 168(1), 205-231.

Flett, G., \& Hewitt, P. (2002). Perfectionism and maladjustment: An overview of theoretical, definitional, and treatment issues. In P. L. Hewitt, \& G. L. Flett (Eds.), perfectionism (pp. 5-31). Washington DC: American Psychological Association. https://doi.org/10.1037/10458-001

Jadidi, F., Mohammadkhani, S., \& Tajrishi, K. (2011). Perfectionism and Academic procrastination. Procedia - Social and Behavioral Sciences, 30(1), 534-537. https://doi.org/10.1016/j.sbspro.2010.07.342

Kachgal, M., Hansen, L., \& Nutter, K. (2001). Academic procrastination prevention/intervention: Strategies and recommendations. Journal of Developmental Education, 25(1), 14-24.

Klassen, R., Krawchuk L., \& Rajani S. (2007). Academic procrastination of undergraduate's low self-efficacy to self- regulate predicts higher levels of procrastination. Contemp. Educ. Psychol., 33(1), 915-931.

Klingsieck, K. (2013). Procrastination: When Good Things Don't Come to Those Who Wait. European Psychologist, 18(1), 24-34. https://doi.org/10.1027/1016-9040/a000138.

Lay, C. (1986). At last, my research article on procrastination. Journal of research in personality, 20(4), 474-495. https://doi.org/10.1016/0092-6566(86)90127-3 


\section{Macrothink}

International Journal of Education ISSN 1948-5476 2017, Vol. 9, No. 3

Lee, E. (2005). The relationship of motivation and flow experience to academic procrastination in university students. J. Genet. Psychol., 166(1), 5-14. http://dx.doi.org/10.3200/GNTP.166.1.5-15.

Lekich, N. (2006). The relationship between academic motivation, self-esteem, and academic procrastination in college student. Unpublished Master's Thesis. Truman State University, Kirksville. Missouri: USA.

Ministry of Education ${ }^{(1)}$, (2017), Laws and Legislations. Retrieved March 20, 2017 from http://www.moe.gov.jo/Departments/DepartmentsMenutails.aspx?Menuu=682\&Depart mentID $=30$

Ministry of Education ${ }^{(2)}$, (2017), Department of Special Education: Department of Talent $\begin{array}{lllll}\text { Programs. } & \text { Retrieved } & \text { March } & 2017 & \text { from }\end{array}$ http://www.moe.gov.jo/Departments/DepartmentsMenutails.aspx?Menuu=693\&Depart mentID=30

Odac1, H. (2011). Academic self-efficacy and academic procrastination as predictors of problematic internet use in university students. Compute. Educ., 57(1), 1109-1113. https://doi.org/10.1016/j.compedu.2011.01.005

Ozer, B., \& Ferrari, J. (2011). Gender orientation and academic procrastination: Exploring Turkish high school students. Individual Differences research, 9(1), 33-40. https://doi.org/10.15694/mep.2017.000055.

Ozer-Bilge, U. (2011). A Cross Sectional Study on Procrastination: Who Procrastinate More. International Conference on Education, Research and Innovation IPEDR. Vol.18 IACSIT Press: Singapore.

Seo, E. (2008). Self-efficacy as a mediator in the relationship between self-oriented perfectionism and academic procrastination. Social Behavior and Personality: Int. J., 36(6), 753-764. https://doi.org/10.2224/sbp.2008.36.6.753.

Seo, E. (2013). Comparison of active and passive procrastination in relation to Academic motivation. Social Behavior and Personality: Int. J., 41(5), 777-786. https://doi.org/10.2224/sbp.2013.41.5.777.

Silverman. L. (2007). Perfectionism: the crucible of giftedness. Gifted Education International, 23(3), 233-245. https://doi.org/10.1177/026142940702300304

Solomon, L., \& Rothblum, E. (1984). Academic procrastination: Frequency and cognitive-behavioral correlates. Journal of counseling psychology, 31(4), 503-509. https://doi.org/10.1037/0022-0167.31.4.503

Steel, P. (2007). The nature of procrastination: A Meta-Analytic and theoretical review of quintessential self-regularity failure. Psychological Bulletin, 133(1), 65-94. https://doi.org/10.1037/0033-2909.133.1.65

Steel, P., Brothen, T., \& Wambach, C. (2001). Procrastination and personality, performance, 
and mood. Personality and Individual Differences, 30(1), 95-106. https://doi.org/10.1016/S0191-8869(00)00013-1

Subotnik, R., Olszewski-Kubilius, P., \& Worrell, Fr. (2011). Rethinking Giftedness and Gifted Education: A Proposed Direction Forward Based on Psychological Science. Psychological Science in the Public Interest, 12(1), 3-54. https://doi.org/10.1177/1529100611418056

Tice, D., \& Baumeister, R. (1997). Longitudinal study of procrastination, performance, stress, and health: The costs and benefits of dawdling. Psychological Science, 8(6), 454-458. http://dx.doi.org/10.1111/j.1467-9280.1997.tb00460.x.

Watson, D. (2001). Procrastination and the five-factor model: a facet level analysis. Pers. Indiv. Differ., 30(1), 149-158. https://doi.org/10.1016/S0191-8869(00)00019-2

Williams, J., Shannon K., Stark, S., \& Foster, E. (2008). Start Today or the Very Last Day? The Relationships among Self Compassion, Motivation, and Procrastination. American Journal of Psychological Research, 4(1), 37-43.

Wolters, C. (2003). Understanding Procrastination from a Self-Regulated Learning Perspective. Journal of. Educational Psychology, 95(1), 179-187. https://doi.org/10.1037/0022-0663.95.1.179

\section{Copyright Disclaimer}

Copyright for this article is retained by the author(s), with first publication rights granted to the journal.

This is an open-access article distributed under the terms and conditions of the Creative Commons Attribution license (http://creativecommons.org/licenses/by/3.0/). 